\title{
A HEADRACE TUNNEL RECONSTRUCTION IN TURKEY
}

\author{
Matouš Hilar ${ }^{a, b, *}$, Martin SRB $^{b}, \mathrm{JAKUB} \mathrm{NOSEK}^{b}$ \\ ${ }^{a}$ Czech Technical University in Prague, Faculty of Civil Engineering, Department of Geotechnics, Thákurova 7, \\ 16629 Prague, Czech Republic \\ b $3 G$ Consulting Engineers Ltd., Na Usedlosti 16, 14700 Prague, Czech Republic \\ * corresponding author: hilar@3-g.cz
}

\begin{abstract}
The operation of a hydro power project in North Turkey started in 2015, included the $12 \mathrm{~km}$ long headrace tunnel. An $8 \mathrm{~km}$ long lower tunnel section was excavated by double shield TBM technology with $8.7 \mathrm{~m}$ ID. Due to problems with the mechanised excavation, a $4 \mathrm{~km}$ long upper tunnel section was excavated conventionally by the Drill and Blast method with single shell lining generated from fibre reinforced sprayed concrete and rock bolts. Significant operational problems were observed in September 2016. The flooded tunnel was investigated by underwater Remotely Operated Vehicle which indicated significant collapses. Operation of the power station had to be stopped and water from a supply dam at the headrace tunnel inlet had to be discharged to enable dewatering and inspection of the tunnel. Consequent investigation revealed three major collapses and a considerable variety of other damages in the D\&B section of the tunnel. Repair and strengthening of the tunnel was completed in October 2017.
\end{abstract}

KEYWORDS: Tunnel, reconstruction, conventional excavation, sprayed concrete, TBM.

\section{INTRODUCTION}

The water tunnel is located in North Turkey in the area of the North Anatolian Fault between the Eurasian plate and the African plate (Figure 1). The lower part of the tunnel is geologically very variable including sandstones, mudstones, conglomerates, ophiolitic and continental units, metalavas, marbles, etc. The upper part of the tunnel is situated in volcanic rocks (basalts and andesites with dykes). The maximum tunnel overburden is about $600 \mathrm{~m}$, and the difference of water tables in upper dam and lower dam is about $80 \mathrm{~m}$. A surge shaft is situated above the tunnel close to the power house.

\section{TunNEL CONSTRUCTION}

The water tunnel excavation by a double-shield TBM technology [1] started from the lower (outfall) portal in February 2012 [2. Traditional reinforced segmental lining $(6+1)$ with $400 \mathrm{~mm}$ thickness, $1.5 \mathrm{~m}$ ring length and internal diameter $8.7 \mathrm{~m}$ was installed during tunnel excavation. Originally mechanical excavation was planned for the whole tunnel, and the segmental lining was proposed only for the initial $3 \mathrm{~km}$ of the tunnel, with the rest intended to be supported with shotcrete and rock bolts. The double-shield was blocked by ground squeezing soon after the start of excavation 3 . The shield had to be released using by-pass adit which was a time-consuming process. This scenario had to be repeated several times during shield excavation due to very unfavourable ground conditions. Thus it was decided to start with a conventional Drill and Blast (D\&B) excavation [4] from the upper (inlet) portal as a mitigation measure to save time. The conventional excavation was realised with full profile using steel fibre reinforced sprayed concrete and CT bolts. Finally a $4 \mathrm{~km}$ tunnel section ending with a dismantling chamber for double-shield was excavated conventionally by Drill and Blast method from the inlet portal, and an $8 \mathrm{~km}$ tunnel section was excavated by shield from the outlet portal. The whole part excavated by shield was permanently supported by segmental lining with steel cages, the whole D\&B part was permanently supported by single-shell steel fibre reinforced sprayed concrete, CT bolts and a cast in situ concrete floor at the tunnel bottom. Excavations were completed in June 2014, and power generation started in August 2015.

\section{InVESTIGATION OF DAMAGE}

Significant problems were observed in the power station in September 2016 (lower water pressure, muddy colour of water, stones in water), and thus its operation had to be stopped. The flooded tunnel was inspected by underwater Remotely Operated Vehicle (ROV) allowing 3D scanning (Figure 2). The inspection revealed three different and bigger failures in the tunnel at approximately $0+210,0+590$ and $3+280$ (chainage starts at the intake portal). The collapse 1 at $3+280$ was the largest, as it obstructed about three quarters of the tunnel profile and did not allow further inspection of the remaining section of D\&B tunnel from $3+280$ to $4+000$ since there was a significant risk that the ROV cable would be trapped in the collapse. The tunnel and upper dam had to be dewatered afterwards, and this procedure took about one month (Figure 1). 


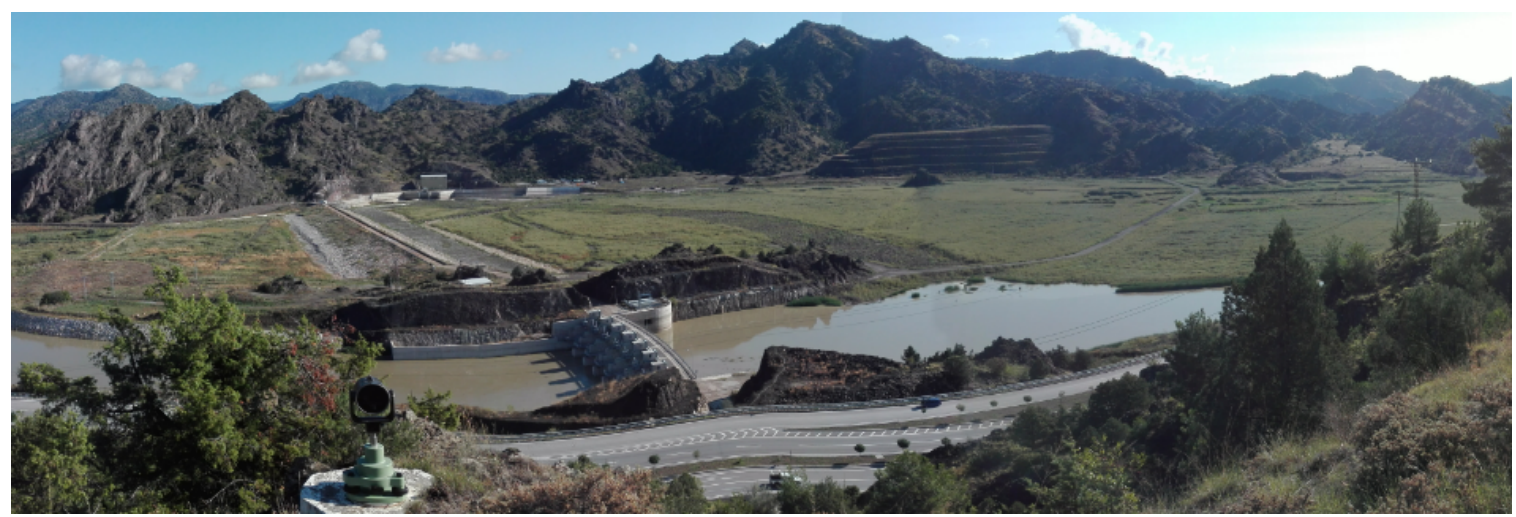

Figure 1. Discharged dam with the inlet structures and mountain range crossed by the headrace tunnel.

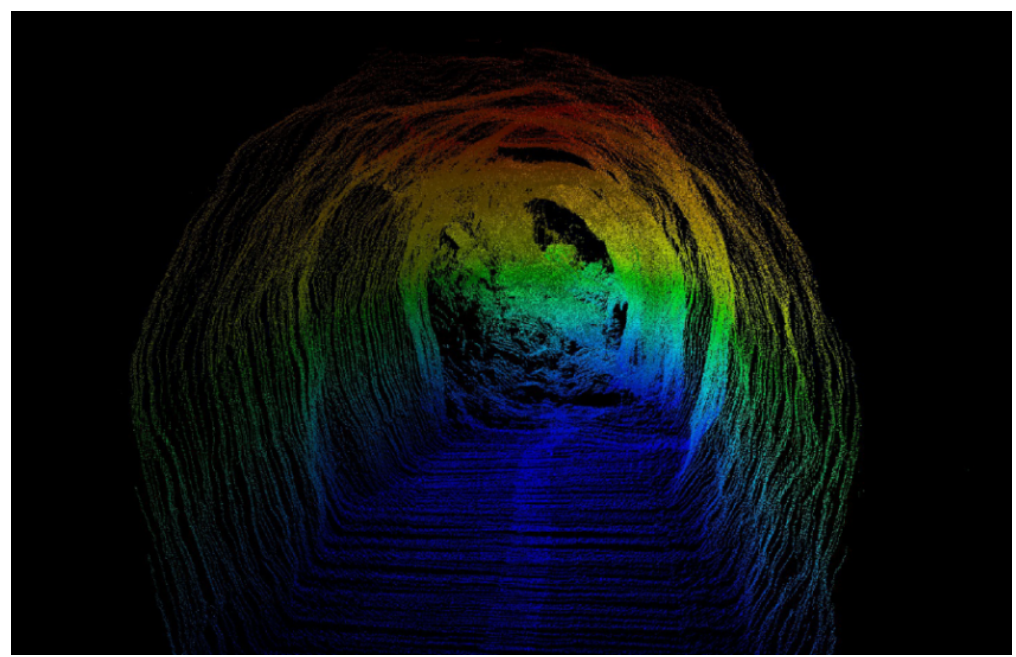

FiguRE 2. Record from scanning of collapsed area by ROV.

An access to the D\&B tunnel was prepared by ramp construction and the opening trash rack at the inlet structure. In November 2016 the D\&B tunnel was inspected by walk from the intake portal to $2+160$ and on a boat (due to water blocked by the collapse) from $2+160$ to $3+280$. Water depth at the collapse 1 blockage was $5.5 \mathrm{~m}$. Also the tunnel with segmental lining was walked through and inspected via access from the outlet portal through a man-hole in penstock in the power house just before the turbines. The collapse $2(3+885)$ and the collapse $3(3+905)$ in the D\&B tunnel were also inspected, and the area between collapse 1 and 2 was flooded. An additional visit was done from the inlet portal, and the collapse 1 was walked through and the area between collapse 1 and collapse 2 in the D\&B tunnel was inspected on boat. Several minor failures were observed in this section. Initial geodetic measurements of the collapses 1, 2, and 3 were completed in January 2017. The geodetic measurements undertaken gave a better idea about the shape of caverns and the volume of fallen material (i.e. the total volume of caverns).

The original survey of collapses and failures was improved later (after accumulated water was discharged and after removal of obstructing material, giving a better access for equipment and machines, with a better lighting, etc.). After the initial investigation of damage, the detailed investigation of damage was conducted and recorded. The detailed inspection was completed for the whole tunnel (i.e. both D\&B tunnel and TBM tunnel). The inspection schedule was affected by accessibility of various sections and some sections were accessible only after the repair of collapses and after water pumping.

\section{Collapses}

\subsection{Collapse 1}

The collapse 1 area (about a $30 \mathrm{~m}$ long tunnel section) starting at $\mathrm{km} 3+280$ (Figure 3 ) was additionally filled by sand and access to the collapse cavern sealed by foam. For ventilation and access behind the collapse, a $30 \mathrm{~m}$ long pipe of $1.2 \mathrm{~m}$ diameter was placed on the top of the blockage before closing the tunnel profile. Also a pipe for water pumping through the collapse 1 was installed prior to its filling. Then the lower part of the cavern generated by the collapse 1 was filled with concrete from the tunnel. Filling of the rest of the cavern was done through boreholes drilled from the surface.

The purpose of surface works above the collapse 1 was a filling of the cavern above the collapse by self- 


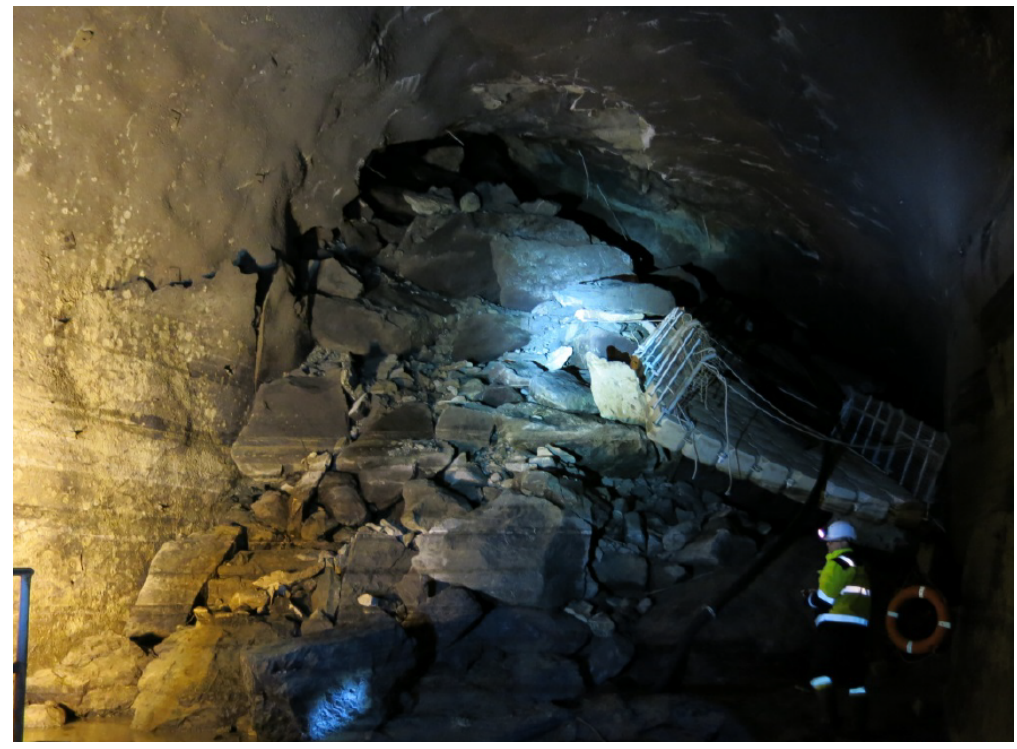

Figure 3 . The collapse 1 after water pumping completion.

levelling concrete. Firstly, the point for drilling had to be determined by surveyors and a road to this area had to be constructed. Then drilling of boreholes started. The first borehole encountered the cavern above the collapse 1 at a depth of $215 \mathrm{~m}$, and it was used for concrete pouring to the cavern. The borehole was equipped with a plastic casing. After some time of concrete pouring the first borehole was blocked by concrete, caused by higher speed of concrete pouring with limited possibilities for air release. The attempt to re-drill the first borehole was not successful. The new drilling did not reach the cavern, and the drill probably deviated from its original direction. Drilling of the second and third boreholes was successful; their depth was also about $215 \mathrm{~m}$.

Completion of the third borehole allowed faster concrete pouring due to air release, with generally about $100 \mathrm{~m}^{3}$ of concrete being poured into the borehole daily. The strong air flow with a smell of concrete was blowing from the third (air release) borehole during concreting of the second borehole, and it confirmed connection of the boreholes via cavern. Concrete pouring to the cavern from the surface was completed in April 2017, with a total of about $3,500 \mathrm{~m}^{2}$ of selfcompacting concrete being poured to the area of the collapse 1 and the cavern above it (approx. $500 \mathrm{~m}^{3}$ from the tunnel and $3,000 \mathrm{~m}^{3}$ from the surface). The situation in the cavern was checked daily by a camera with attached lights lowered to the boreholes from the surface on a cable.

Tunnel lining strengthening in front of the collapse 1 area was realised prior to start of re-excavation. This was needed to generate a safe working area to minimize the risk for the working crews. A systematic rockbolting using $6 \mathrm{~m}$ long galvanised SN bolts was done from $3+240$ to $3+270$. Additional support using steel meshes, lattice girders and shotcrete was installed as from $\mathrm{km} 3+265$ to $\mathrm{km} 3+270$. Then conventional excavation of top heading with $1 \mathrm{~m}$ advances through the collapse 1 was carried out. Applied support included sprayed concrete, steel meshes, lattice girders, $6 \mathrm{~m}$ long galvanised rockbolts SN or IBO, umbrellas from $8 \mathrm{~m}$ long IBO 51 bolts, etc. Probe drilling with a length up to $15 \mathrm{~m}$ was conducted every $6 \mathrm{~m}$. All voids encountered by drilling were filled by cement grout. Material removal from the bench area started afterwards. Excavation was initially ongoing on the right side from the downstream view, then bench excavation on the left side started. The original tunnel lining in the bench area was not damaged, thus material removal and installation of support was straightforward. Only very low deformations below $20 \mathrm{~mm}$ were recorded during re-excavation due to successful filling by concrete and grout.

\subsection{Collapse 2}

Breakthrough to the collapse 1 allowed access to the collapse 2. However, the area between the collapses 1 and 2 was flooded, and had to be dewatered. After water pumping completion, access could be cleaned up and the collapse 2 could be investigated. Investigation revealed about a $34 \mathrm{~m}$ high and a $5 \mathrm{~m}$ wide cavern with the shape of a square vertical chimney. The cavern mouth was situated on the left shoulder at $\mathrm{km} 3+885$. Strengthening of area ahead of the collapse 2 started afterwards, with shotcrete spraying and rockbolting being realised. Removal of collapsed material followed. Then initial support was partly installed, but working was slow due to safety concerns (risk of falling stones from the cavern). A decision was taken to cover the cavern by the high-tensile steel mesh MINAX 80/3 (Figure 4). After initial support and permanent rockbolting up to $3+880$, the first meshes and 13 lattice girders were installed over the cavity opening from $3+878$ to $3+890$. The area was sprayed by shotcrete and plastic pipes were installed 
through the lining to allow concrete pouring into the cavern. Pumping of the self-levelling concrete C35 into the cavern started after tunnel lining under the collapse 2 (including permanent rockbolting, second meshes covered by shotcrete, and also the left side propping). The pumping was slower in the beginning; speed was increased once the concrete level reached $2 \mathrm{~m}$ above the tunnel crown. The pipes for concrete pouring and air release were extended 3-times during concreting using a telescopic piping arrangement, and finally pipes reached the cavern roof. About $50 \mathrm{~m}^{3}$ of concrete was pumped per day. Then, grouting of voids and open spaces behind the lining was carried out. The collapse 2 cavern filling was completed in July 2017, involving a pumping of about $800 \mathrm{~m}^{3}$ of concrete in total.

\subsection{Collapse 3}

Installation of the high-tensile steel mesh MINAX 80/3 over the collapse 2 before its filling allowed safe access to the collapse 3. A narrow mouth of the collapse 3 was situated to the right side wall at $\mathrm{km} 3+905$, and as the mouth was blocked by a bigger block of rock, it did not allow sight and survey of the cavern behind it. After strengthening of the area, probe drilling performed by a standard tunnel boomer started, with the length of drills varied from 6 to $9 \mathrm{~m}$. Generally loose material was encountered by probe holes, but no big cavern was detected. Drilling machine for longer drills was also utilised, and the purpose of longer drills was to locate a cavern in higher areas. Probe hole 20 drilled from $3+912$ reached a length $32 \mathrm{~m}$, and as it encountered a loose material, it was used for grouting (Figure 5) with a packer $9 \mathrm{~m}$ deep. During grouting leakage in the cavern mouth area was observed which confirmed the connection of loose areas. After the probe hole 20 blockage, it was re-drilled by the probe hole 21. Grouting was finalized by probe hole 22 which was crossing the probe hole 21 in a diagonal way. When a leakage from the hole 21 was observed during grout pumping into the hole 22 , it was confirmed that the whole possible cavern was reasonably filled. Some additional systematic $6 \mathrm{~m}$ long drilling and grouting was performed afterwards. In total over $300 \mathrm{~m}^{3}$ of grout was pumped into the collapse 3 area.

Then material removal from the bench in area of collapses 2 and 3 started. Excavation was ongoing from downstream side; upper $2 \mathrm{~m}$ of bench were removed on the whole section. Then excavation continued from upstream side and the lower part of bench was removed. Original tunnel lining inspection was done after removal of material from bench area of the collapses 2 and 3. Original lining in bench area was disturbed on two locations - under the collapse 2 mouth and under the collapse 3 mouth. Both areas of exposed ground were covered by a $10 \mathrm{~cm}$ thick layer of sprayed concrete as temporary support. Lining damage under the collapse 2 exposed about $5 \mathrm{~m}^{2}$ of ground. The lining damage was not connected with the cavern mouth, and a reasonably hard original rock was exposed in the area. Lining damage under the collapse 3 was different. The area of exposed ground was about $7 \mathrm{~m}$ long and $4 \mathrm{~m}$ high (i.e. about $28 \mathrm{~m}^{2}$ ). A very soft ground was exposed, and it was probably collapsed material washed out by water from rock mass after the collapse. The support of bench corresponded with top heading support. Permanent rockbolting by galvanized SN bolts was carried out. Two layers of meshes with lattice girders were installed under the collapse 2. Other areas were supported by 2 layers of steel meshes covered by shotcrete. Bench support installation was completed together with completion of all strengthening works of the $\mathrm{D} \& \mathrm{~B}$ tunnel at the beginning of November 2017.

\section{TUNnEl SECTION With SEgMENTAL LINING}

Repair of the tunnel section excavated by doubleshield with segmental lining was significantly affected by a limited access. Access for people to this section was originally allowed by a small opening in the steel tube in the area of the power station. The second access was allowed by a surge shaft situated close to the power station. Preparatory work to get an access through the shaft started in April 2017 - installation of crane with basket, arrangement of safety measures, etc. Access from the intake portal was affected by collapses and activities in the D\&B tunnel, with a barrier separating the segmental tunnel and the dismantling chamber in D\&B tunnel being removed in July 2017. However, a good access was ensured after completion of the bench excavation in the collapse 2 and 3 areas. Work in the segmental tunnel section started with core drilling in May 2017 using access though the surge shaft (Figure 6). Only problematic sections were investigated by core drilling. $5 \mathrm{~m}$ long cores were taken from 5 locations in each profile (9:00, 10:30, 12:00, 1:30, 3:00). Pressure water tests were realised in drills after removal of cores. Trial grouting in the segmental tunnel section started in June 2017. It was executed on 18 rings (27 metres). Grouting continued afterwards on other problematic sections, with a total of 6 sections being grouted. Trial grouting was done through 5 drills in each profile (9:00, 10:30, 12:00, $1: 30,3: 00)$, then the number of drills in each profile was reduced to 3 (11:00, 12:00, 1:00) and then only to 1 (12:00). Repair of damaged segments was done in September 2017. The worst section of segmental lining (about 11 rings) included cracked segments with exposed reinforcement. Problematic segments had to be repaired (removal of loose concrete, cleaning of area, covering by appropriate material). Steel ribs (galvanized HEB 260 profiles) were installed to the section. Also permanent rockbolting and grouting was completed. 


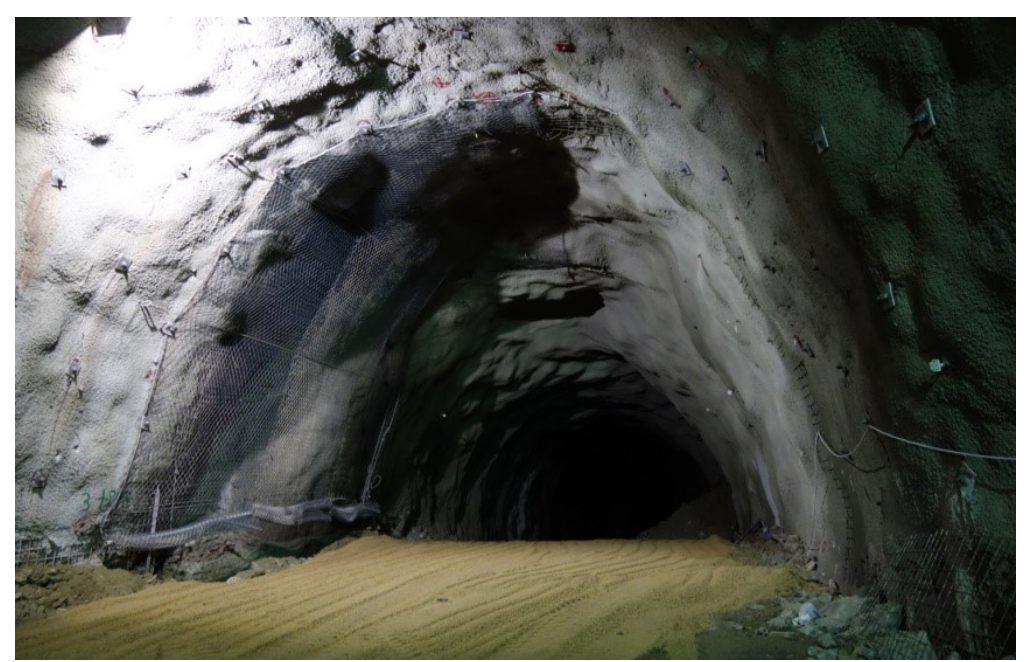

FiguRE 4 . The collapse 2 mouth protection by the high-tensile steel mesh.

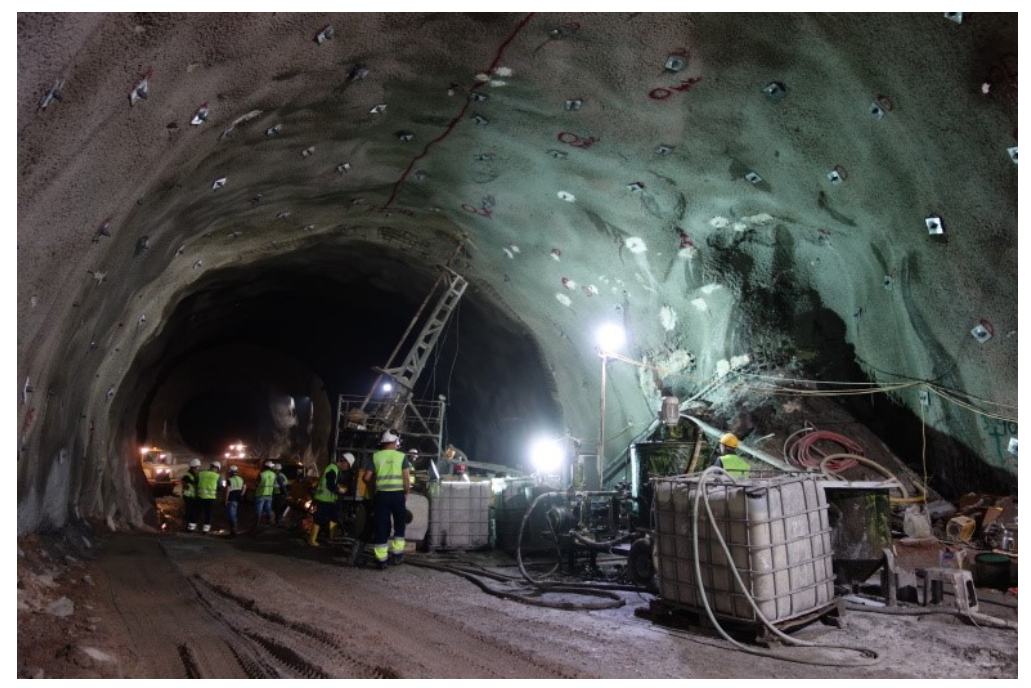

FiguRE 5. Grouting of the collapse 3, its mouth situated behind a barrel with grout.

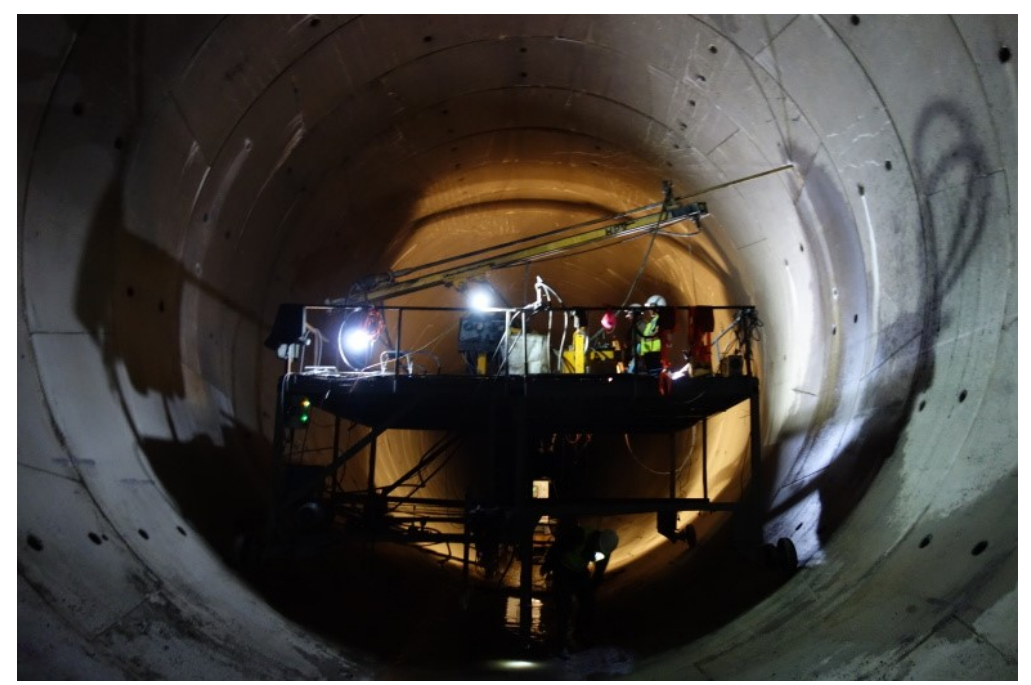

Figure 6. Core drilling in the TBM tunnel. 


\section{Conclusions}

Very specific and rare problems had to be solved during the water tunnel repair (collapses of the operated tunnel with a volume in thousands of $\mathrm{m}^{3}$ ) and with a very significant time pressure. The tunnel repair was completed within approximately one year. Preparation took about half a year (investigation of problems, draining the dam, preparation of contracts, design, site preparation, provision of machines and materials, etc.). Reconstruction took about another half-year (repair of three big collapses, repair of many minor failures, strengthening of the D\&B tunnel, repairs and grouting of segmental lining). It is difficult to estimate the lifetime of the finalised repairs, but it is possible to expect that further repairs may be required in the future based on observations and measurements. The tunnel will be regularly inspected by ROV (in roughly half-year intervals). The whole D\&B tunnel and problematic sections of the tunnel section with segments were scanned and geodetically measured. Thus, future tunnel lining deformations can be checked after dewatering of the tunnel to allow access for surveyors. Detailed design and construction preparation will have to be done prior to further repair in order to ensure that the final solution will be optimal from both structural (functionality, quality, life time, etc.) and financial viewpoints (repair cost including impact of interruption of energy generation).

\section{ACKNOWLEDGEMENTS}

Financial support from the TAČR grant TE01020168 is gratefully acknowledged.

\section{REFERENCES}

[1] G. Girmscheid, C. Schexnayder. Tunnel boring machines. Practice Periodical on Structural Design and Construction 8(3), 2003. DOI:10.1061/(ASCE)1084-0680(2003)8:3(150).

[2] J. Clark, S. Chorley. The greatest challenges in tbm tunneling: Experiences from the field. In Proceedings of the conference North American Tunneling, chap. 12. Knovel, 2014.

[3] G. Anagnostou, K. Kovári. Tunnelling through geological fault zones. In Proceedings of International symposium on design, construction and operation of long tunnels. ETH Library, Zürich, 2005.

[4] G. Girmscheid, C. Schexnayder. Drill and blast tunneling practices. Practice Periodical on Structural Design and Construction 7(3), 2002. DOI:10.1061/(ASCE)1084-0680(2002)7:3(125). 